\title{
Role of Oatp2b1 in Drug Absorption and Drug-Drug Interactions ${ }^{\text {『 }}$
}

\author{
Mingqing Chen, Shuiying Hu, Yang Li, Alice A. Gibson, Qiang Fu, Sharyn D. Baker, \\ and Alex Sparreboom
}

\author{
Experimental Cancer Pharmacology Laboratory, Division of Pharmaceutics and Pharmacology, College of Pharmacy, The Ohio \\ State University, Columbus, Ohio
}

Received December 23, 2019; accepted February 18, 2020

\section{ABSTRACT}

The organic anion transporting polypeptide (OATP)2B1 is localized on the basolateral membrane of hepatocytes and is expressed in enterocytes. Based on its distribution pattern and functional similarity to OATP1B-type transporters, OATP2B1 might have a role in the absorption and disposition of a range of xenobiotics. Although several prescription drugs, including hydroxymethylglutarylcoenzyme A-CoA reductase inhibitors (statins) such as fluvastatin, are OATP2B1 substrates in vitro, evidence supporting the in vivo relevance of this transporter remains limited, and most has relied on substrate-inhibitor interactions resulting in altered pharmacokinetic properties of the victim drugs. To address this knowledge deficit, we developed and characterized an Oatp2b1-deficient mouse model and evaluated the impact of this transporter on the absorption and disposition of fluvastatin. Consistent with the intestinal localization of Oatp2b1, we found that the genetic deletion or pharmacological inhibition of Oatp2b1 was associated with decreased absorption of fluvastatin by 2- to 3-fold. The availability of a viable Oatp2b1deficient mouse model provides an opportunity to unequivocally determine the contribution of this transporter to the absorption and drug-drug interaction potential of drugs.

\section{SIGNIFICANCE STATEMENT}

The current investigation suggests that mice deficient in Oatp2b1 provide a valuable tool to study the in vivo importance of this transporter. In addition, our studies have identified novel potent inhibitors of OATP2B1 among the class of tyrosine kinase inhibitors, a rapidly expanding class of drugs used in various therapeutic areas that may cause drug-drug interactions with OATP2B1 substrates.

\section{Introduction}

Organic anion transporting polypeptides (human: OATPs, gene: SLCO; rodent: Oatps, gene: Slco) are transporters involved in the uptake of multiple clinically important drugs as well as endogenous compounds. In particular, OATP1B1 (SLCO1B1) and OATP1B3 (SLCO1B3) are involved in the hepatocellular uptake of numerous xenobiotic and endogenous metabolites, and this recognition has resulted in the release of a Food and Drug Administration guidance on drug-drug interaction studies for investigational agents that act as substrates or inhibitors of this transport mechanism. A third OATP expressed in the liver, OATP2B1 (SLCO2B1), is less well characterized, although it shows substrate overlap with OATP1B-type transporters. OATP2B1 also exhibits broader tissue expression, it is the main OATP expressed in the intestine (Drozdzik et al., 2014), and its function is distinctly $\mathrm{pH}$-sensitive with enhanced activity observed under acidic $\mathrm{pH}$ (Nozawa et al., 2004; Varma et al., 2011). Based on these properties, it has been suggested that OATP2B1 might be involved in the oral absorption of drugs, although its precise localization in enterocytes

The work was supported in part by the National Institutes of Health [Grants R01CA215802 (to A.S.), R01CA238946 (to S.H.), and R01CA138744 (to S.D.B.)], by the Ohio State University Comprehensive Cancer Center using Pelotonia funds and by Eli Lilly student fellowship offered by the Ohio State University (20182019). The content is solely the responsibility of the authors and does not necessarily represent the official views of the funding agencies.

https://doi.org/10.1124/dmd.119.090316.

S This article has supplemental material available at dmd.aspetjournals.org. remains controversial (Kobayashi et al., 2003; Keiser et al., 2017). Most in vivo evidence for intestinal OATP2B1 as a mediator of oral absorption comes from drug interaction studies involving inhibitors, including fruit juices, which have indicated decreases in measures of systemic exposure to a number of OATP2B1 substrates, including fexofenadine, atorvastatin, and rosuvastatin (Akamine et al., 2014; Fujita et al., 2016; Johnson et al., 2017; Kashihara et al., 2017).

Recent proteomics data indicating overlapping expression profiles of OATP2B1 and OATP1B3 in the liver (Badée et al., 2015; Prasad et al., 2016) have also put forward the thesis that OATP2B1 may be involved directly in liver uptake and indirectly in biliary excretion of xenobiotic substrates. However, because of the overlapping substrate and inhibitor specificity with OATP1B-type transporters, the actual independent contribution of OATP2B1 to liver uptake remains unclear. Using positron emission tomography scans of $\left[{ }^{11} \mathrm{C}\right]$-erlotinib, an epidermal growth factor receptor tyrosine kinase inhibitor (TKI), it was recently shown that its cellular accumulation is increased in A431 cells overexpressing OATP2B1, but not OATP1B1/OATP1B3, and that uptake of erlotinib in the liver of human subjects is decreased by pretreatment with the OATP inhibitor, rifampin (Bauer et al., 2018b). As the transport-inhibitory properties of compounds such as rifampin are not limited to OATP2B1, conclusive evidence of causality remains to be demonstrated, and additional approaches are required to bridge the gap between in vitro assays and clinical observations. This need is exemplified by the notion that OATP2B1 has been recognized as a transporter of emerging clinical importance by the International Transporter Consortium, as its exclusion from mechanistic consideration

ABBREVIATIONS: AUC, area under the curve; E3S, estrone sulfate; OATP, organic anion transporting polypeptide; PCR, polymerase chain reaction; qPCR, quantitative PCR; TKI, tyrosine kinase inhibitor. 
may lead to inaccurate in vitro to in vivo extrapolation of transportermediated clearance and drug-drug interaction predications (ZamekGliszczynski et al., 2018). Since OATP2B1 has only a single mouse ortholog (Oatp2b1) with high sequence homology and a similar tissue expression profile compared with the human transporter (Chu et al., 2013), the use of single gene knockout models can provide translationally useful information regarding the biologic role of this transporter in humans. In this report, we describe the generation and characterization of such an Oatp2b1-deficient mouse model and its application to pharmacokinetic studies with fluvastatin, a known OATP2B1 substrate, administered orally and intravenously in the presence or absence of the OATP2B1 inhibitor, erlotinib (Noé et al., 2007; Bauer et al., 2018a).

\section{Materials and Methods}

Chemicals and Reagents. Positive control substrates, including $\left[{ }^{3} \mathrm{H}\right]$ fluvastatin lactone $\left(20 \mathrm{Ci} / \mathrm{mmol}, 98 \%\right.$ radiochemical purity) and $\left[{ }^{3} \mathrm{H}\right]$-estrone sulfate (E3S) $(50 \mathrm{Ci} / \mathrm{mmol}, 99 \%$ radiochemical purity), were obtained from American Radiolabeled Chemicals (St. Louis, MO). Unlabeled fluvastatin was from SelleckChem (Houstin, TX), and TKI reference standards and other chemicals were obtained at the highest purity available from various commercial sources.

Generation of an OATP2B1-Deficient Mouse Model. Oatp2b1-deficient mice were established in a C57BL/6N background from heterozygous embryos purchased from the University of California Davis Knockout Mouse (KOMP) Repository (www.komp.org) through Flp-Frt and Cre-loxP recombination. Detailed allele conformation is shown in Fig. 1A, and a schematic breeding strategy is illustrated in Fig. 1B. Briefly, rederived mice with Slco $2 \mathrm{~b} 1^{\mathrm{tmla(KOMP)}}$ ${ }^{\text {Wtsi }}$ allele $\left(\mathrm{F}_{0}\right)$ were first crossed with mice expressing Flp recombinase. Offspring with Slco2b $1^{\text {tmlc }}$ allele $\left(\mathrm{F}_{1}\right)$ were crossed with mice expressing Cre recombinase that recognizes the loxP site to cut out the targeted exon. Offsping with the resulting Slco $2 \mathrm{~b} 1^{\text {tmld }}$ allele $\left(\mathrm{F}_{2}\right)$ were confirmed to carry heterozygous genotypes. Genotyping primers were as follows: loxP forward (5'-GAGATGGCGCAACGC AATTAATG- $3^{\prime}$ ) and loxP reverse (5' - ATAGCCAAGGAGAGCCTAGAACTT C-3'), wild-type/knockout forward (5'-AGATGGGTCTCAGCGTAATGCTAC TC-3'), wild-type reverse (5'-ATAGCTGGGAAGTCAAGGTCAGCCT-3'), and knockout reverse (5'- ATAGCCAAGGAGAGCCTAGAACTTC- ${ }^{\prime}$ ). All mice were housed in a temperature-controlled environment with a 12-hour light cycle and were given a standard diet and water in accordance with guidelines issues by the Ohio State University Institutional Animal Care and Use Committee. All experiments were carried out in accordance with the Guide for the Care and Use of Laboratory Animals as adopted and promulgated by the US National Institutes of Health.

Real-Time Polymerase Chain Reaction and Reverse-Transcription Polymerase Chain Reaction. Organs and tissues were harvested from both wild-type and knockout mice between 8 and 12 weeks of age, snap frozen, and stored at $-80^{\circ} \mathrm{C}$ until RNA isolation. Total RNA was extracted with the E.Z.N.A. Total RNA Kit I (Bio-Tek, Winooski, VT), followed by cDNA synthesis with qScript XLT cDNA SuperMix (QuantaBio, Beverly, MA). Real-time polymerase chain reaction (PCR) was performed on QuanStudio 3 (Thermo Fisher Scientific, Waltham, MA) using TaqMan probes for Oatp2b1 and Oatp1b2 (Thermo Fisher Scientific) and QuantiTect SYBR Green PCR reagents for Abcc2 (Mrp2), Cyp2c65, and Cyp2c66 (Qiagen, Hilden, Germany).

Serum Biochemistry Analysis. Serum was collected from four male and four female age-matched wild-type and knockout mice through cardiac puncture and was stored at $-80^{\circ} \mathrm{C}$ until analysis. Clinical chemistry profiling of the samples was performed by the Comparative Pathology and Mouse Phenotyping Shared Resource at the Ohio State University.

Cell Cultures and Transport Studies. HEK293 cells overexpressing OATP2B1 were generated by transfecting pCMV6-empty plasmid containing OATP2B1 cDNA (Origene, Rockville, MD) and were maintained in Dulbecco's modified Eagle's medium with 10\% FBS. For uptake assays involving Oatp2b1, HEK293T cells were transfected with either pCMV6-AC-IRES-GFP plasmid (Origene, Genescript for cloning) inserted with Oatp2b1 cDNA or empty vector 24 hours before uptake studies. Uptake and inhibition experiments with probe substrates were performed as described previously (Chen et al., 2020). Briefly, cells were preincubated with tested inhibitors (final concentration, $10 \mu \mathrm{M}$ ) in warm phenol-red and FBS-free Dulbecoo's modified Eagle's medium for
15 minutes before 5-minute uptake of E3S (final total concentration, $2.5 \mu \mathrm{M}$ ) in the presence or absence of inhibitors. Transport was terminated by washing cells with ice-cold buffer and by lysing cells in $1 \mathrm{M} \mathrm{NaOH}$ for 4 hours, followed by neutralization with $2 \mathrm{M} \mathrm{HCl}$ for 0.5 hour. Intracellular drug accumulation was quantified by liquid scintillation counting, and results were normalized to total protein concentration as measured by a Pierce BCA Protein Assay Kit (Thermo Fisher Scientific).

Pharmacokinetic Experiments. Adult (8-14 weeks of age) male and female mice were used in all experiments after an overnight fast. Pharmacokinetic studies were performed as described previously (Leblanc et al., 2018). Briefly, fluvastatin $(10 \mathrm{mg} / \mathrm{kg})$ was dissolved in normal saline kept at $37^{\circ} \mathrm{C}$ immediately before oral or intravenous dosing. Erlotinib $(100 \mathrm{mg} / \mathrm{kg})$ was suspended in $0.2 \%$ carboxymethylcellulose $/ 0.1 \%$ Tween- 80 and given orally 1 hour before fluvastatin administration in select experiments. Serial blood samples were taken from individual mice at 5, 15, and 30 minutes from the submandibular vein, at 1 and 2 hours from the retro-orbital sinus, and at 4 hours by a terminal cardiac puncture. Livers were collected at the final time point. All blood samples were centrifuged at $1500 \mathrm{~g}$ for 5 minutes. Tissues were homogenized in five volumes (w/v) of water for analysis, and all samples were stored frozen at $-80^{\circ} \mathrm{C}$ until analysis by a validated method based on liquid chromatography with tandem mass spectrometric detection.

Measurement of Fluvastatin Concentrations. The liquid chromatography with tandem mass spectrometric detection system consisted of a Vanquish UHPLC system, a TSQ Quantum Ultra triple quadrupole mass spectrometer from Thermo Fisher Scientific, and Thermo Trace Finder General Quan system software (version 3.3). An Accucore Vanquish C18 column $(100 \times 2.1 \mathrm{~mm}, \mathrm{dp}=$ $1.5 \mu \mathrm{m}$; Thermo Fisher Scientific) was protected by a corresponding XBridge$\mathrm{BEH} \mathrm{C} 18,5-\mu \mathrm{m}$ guard column. The injection volume was $5.0 \mu 1$. The temperature of the autosampler rack was $4^{\circ} \mathrm{C}$, and the column temperature was maintained at $40^{\circ} \mathrm{C}$. Mobile phase A consisted of water with $0.1 \%(\mathrm{v} / \mathrm{v})$ formic acid, and mobile phase B consisted of acetonitrile:methanol (1:3) with $0.1 \%(\mathrm{v} / \mathrm{v})$ formic acid. The total run time was 5 minutes. The optimized gradient 1 started at 0-0.5 minutes with $10 \% \mathrm{~B}$; 0.5-3.0 minutes, $95 \% \mathrm{~B} ; 3.0-4.0$ minutes, $95 \% \mathrm{~B}$; $4.0-4.1$ minutes, $10 \% \mathrm{~B}$; and $4.1-5.0$ minutes, $10 \% \mathrm{~B}$. The flow rate was set at $0.4 \mathrm{ml} / \mathrm{min}$. The positive voltage applied to the electrospray ionization capillary was $3500 \mathrm{~V}$, and the capillary temperatures was $342^{\circ} \mathrm{C}$ with a vaporizer temperature of $358^{\circ} \mathrm{C}$. Argon was used as a collision gas at a pressure of 1.5 mTorr. Precursor molecular ions and product ions for fluvastatin $(412.28>$ $224.04)$ and fluvastatin-D6 $(417.30>286.11)$ were comfirmed. Assay validation studies performed with independently prepared quality control samples revealed that the within-day precision, between-day precision, and accuracy were $1.82 \%-8.97 \%, 4.76 \%-8.54 \%$, and $96.6 \%-113 \%$, respectively. The linear range of response of calibration curves was $5-1000 \mathrm{ng} / \mathrm{ml}\left(\mathrm{r}^{2}>0.99\right)$, and the lower limit of quantification was $5 \mathrm{ng} / \mathrm{ml}$. The validation characteristics of this assay were considered to be acceptable for the purpose of its implementation in pharmacokinetic studies with fluvastatin.

Data Analysis. All data are presented as means \pm S.E.M. unless stated otherwise, and statistical analyses were performed with an unpaired $t$ test using Prism version 7.0 (GraphPad Software, San Diego, CA). $P$ values $<0.05$ were considered statistically significant. Area under the curve (AUC) and $\mathrm{C}_{\max }$ were calculated using noncompartmental analysis with the software package Phoenix WinNonlin version 7.0 (Certara USA, Princeton, NJ). Fluvastatin concentrations in liver tissue were corrected for contaminating plasma (20.2\% of liver weight) as described by Kaliss and Pressman, 1950.

\section{Results}

Generation of Oatp2b1-Deficient Mice. $\mathrm{F}_{0} \mathrm{~S}$ were identified through $\mathrm{PCR}$, and the loxP sequence (283 bp) was detected in animals 1, 3, 4, and 6 (Fig. 1C). After Frt-Flp recombination $\left(\mathrm{F}_{1}\right)$, Cre-loxP recombination $\left(F_{2}\right)$, and inbreeding of $F_{2}$, wild-type (463 bp, $1318 \mathrm{bp}$ ) and knockout animals with successful deletion of exon 4 (616 bp) were identified (Fig. 1D). Homozygous mice appeared to develop normally to adulthood, reproduced without observable deficits, and lacked noticeable phenotypic alterations compared with wild-type littermates. Deletion of the Oatp2b1 gene was confirmed through real-time quantitative PCR (qPCR) on major organs in which mRNA transcripts remained below the limit of detection (Fig. 1E). The expression levels of Oatp2b1 in different 
A

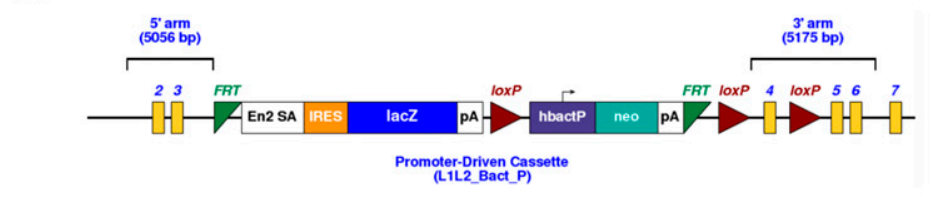

B

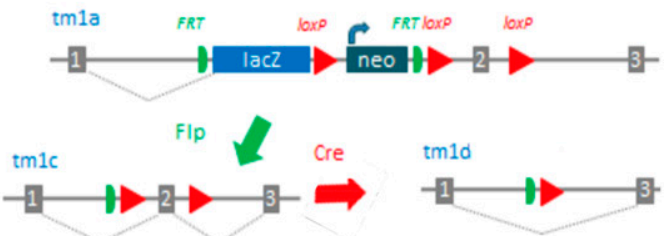

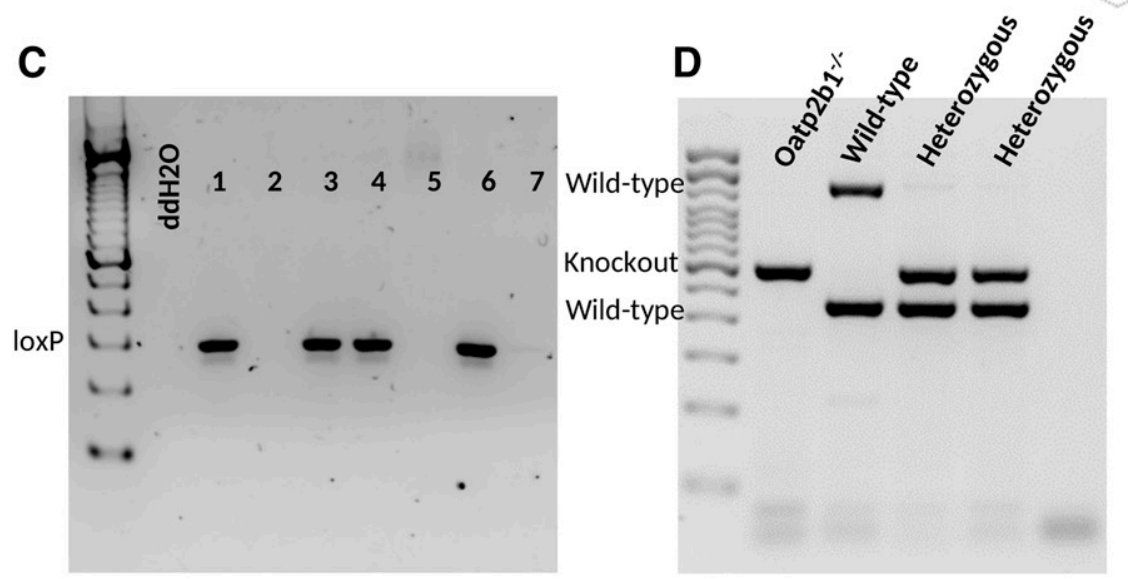

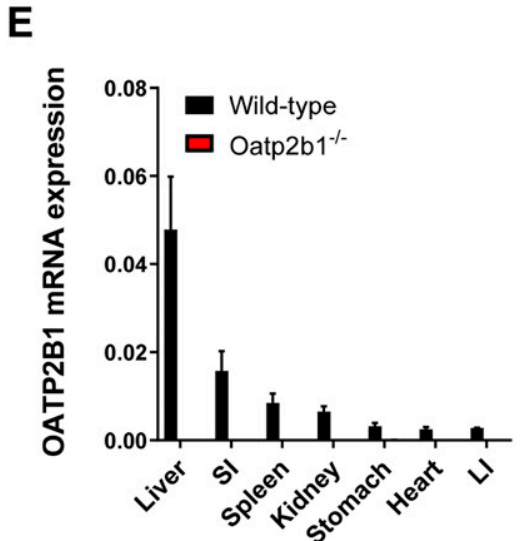

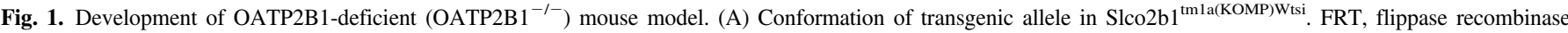

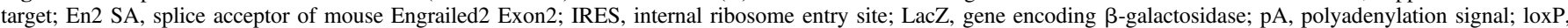

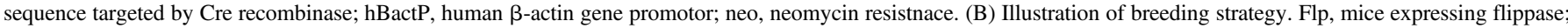

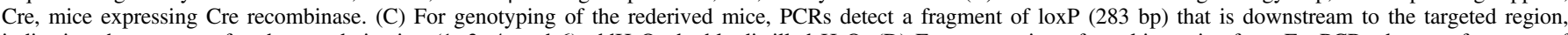

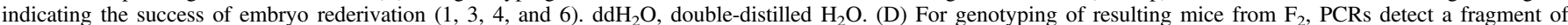

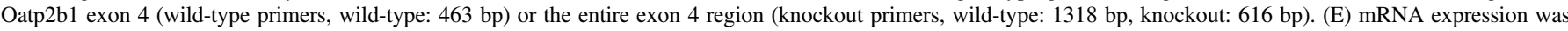
assessed by real-time qPCR, and levels were undetectable in major organs of Oatp2b1-deficient mice. LI, large intestine; SI, small intestine.

intestinal regions was also evaluated in littermate wild-type mice and indicated that transcripts were highest in ileum (Supplemental Fig. 1), in line with a previous report (Meier et al., 2007).

Characterization of Oatp2b1-Deficient Mice. Comprehensive profiling of serum biochemistry markers in Oatp2b1-deficient mice did not reveal any significant changes in markers of liver function, such as alkaline phosphatase, alanine aminotransferase, aspartate aminotransferase, gamma glutamyl transferase, and total bilirubin. Likewise, markers of renal function, such as calcium, creatinine, and creatine kinase, were not significantly altered, except for blood urea nitrogen, which was modestly increased compared with wild-type mice $(21.1 \mathrm{mg}$ / dl vs. $16.9 \mathrm{mg} / \mathrm{dl} ; P<0.05)$ (Table 1$)$.

Pharmacokinetics of Fluvastatin in Oatp2b1-Deficient Mice. After confirming fluvastatin transport in HEK293T cells transiently transfected with plasmids containing Oatp2b1 cDNA (Supplemental Fig. 2), the pharmacokinetic profiles of fluvastatin were evaluated in both male and female mice, wild-type and Oatp2b1-deficient, after oral and intravenous administration. These studies showed that, after oral administration, the AUC of fluvastatin was decreased by about 2-fold in male knockout mice (Fig. 2A) and by about 3-fold in female knockout mice (Fig. 2B). No differences in liver concentrations of fluvastatin between mouse genotypes were detected at 4 hours after drug administration, regardless of sex (Fig. 2C), and liver to plasma ratios were also independent of sex (Supplemental Fig. 3). Measures of systemic exposure to fluvastatin were slightly decreased in male knockout mice after intravenous administration $(19.8 \pm 1.53 \mu \mathrm{g} \times$ $\mathrm{h} / \mathrm{ml}$ vs. $12.6 \pm 0.58 \mu \mathrm{g} \times \mathrm{h} / \mathrm{ml} ; P<0.05$ ), but not in females (Table 2 ). No significant differences between wild-type and knockout mice were detected in the clearance of fluvastatin, regardless of sex (Fig. 2, D and E), suggesting that the influence of Oatp2b1 deficiency on fluvastatin pharmacokinetics is determined by an absorption-mediated process. This is consistent with the notion that the absolute oral bioavailability of fluvastatin was decreased in both female (from $31.5 \%$ to $12.8 \%$ ) and male knockout mice (from $29.6 \%$ to $20.5 \%$ ).

Transporter and Enzyme Profiling. To further validate our observations with fluvastatin in the knockout mice, we evaluated whether compensatory changes occurred in the expression of other putative fluvastatin transporters and metabolizing enzymes. Expression levels of Oatp1b2, Abcc2 (Mrp2), Cyp2c65, and Cyp2c66 were determined in small intestinal and liver samples from both sexes by real-time qPCR. The

TABLE 1

Serum biochemistry comparing wild-type mice and Oatp2b1-deficient mice

Data are presented as means \pm S.E.M. of combined male and female mice $(n=3$ to 4 per genotype per sex).

\begin{tabular}{lrc}
\hline Parameter & Wild-type & Oatp2b1-knockout \\
\hline Albumin (g/dl) & $3.01 \pm 0.25$ & $3.45 \pm 0.16$ \\
Alkaline phosphatase (U/l) & $106 \pm 22.0$ & $134 \pm 19.2$ \\
Alanine aminotransferase (U/l) & $22.4 \pm 5.79$ & $20.9 \pm 4.07$ \\
Amylase (U/l) & $750 \pm 68.3$ & $827 \pm 19.2$ \\
Aspartate aminotransferase (U/l) & $82.6 \pm 12.0$ & $81.9 \pm 6.62$ \\
Blood urea nitrogen (mg/dl) & $16.9 \pm 0.63$ & $21.1 \pm 0.52$ \\
BUN/creatinine & $49.7 \pm 7.21$ & $90.1 \pm 20.5$ \\
Calcium (mg/dl) & $10.0 \pm 0.19$ & $10.2 \pm 0.1$ \\
Cholesterol (mg/dl) & $87.1 \pm 6.16$ & $100 \pm 5.21$ \\
Creatine kinase (U/l) & $202 \pm 44.2$ & $299 \pm 46.6$ \\
Creatinine (mg/dl) & $0.32 \pm 0.03$ & $0.29 \pm 0.03$ \\
Gamma glutamyl transferase (U/l) & $4.67 \pm 0.42$ & $4.38 \pm 0.53$ \\
Globulin (g/dl) & $2.18 \pm 0.27$ & $2.43 \pm 0.21$ \\
Glucose (mg/dl) & $289 \pm 32.6$ & $228 \pm 10.3$ \\
Lipids (U/l) & $65.71 \pm 8.31$ & $61.5 \pm 2.04$ \\
Phosphorus (mg/dl) & $10.9 \pm 1.32$ & $8.63 \pm 0.84$ \\
Total bilirubin (mg/dl) & $0.29 \pm 0.03$ & $0.29 \pm 0.08$ \\
Total protein (g/dl) & $5.28 \pm 0.35$ & $5.86 \pm 0.07$ \\
Triglycerides (mg/dl) & $81.4 \pm 3.42$ & $82.6 \pm 8.64$ \\
\hline
\end{tabular}

BUN, blood urea nitrogen.

$* P<0.05$ vs. wild-type (two-sided student t-test). 
A

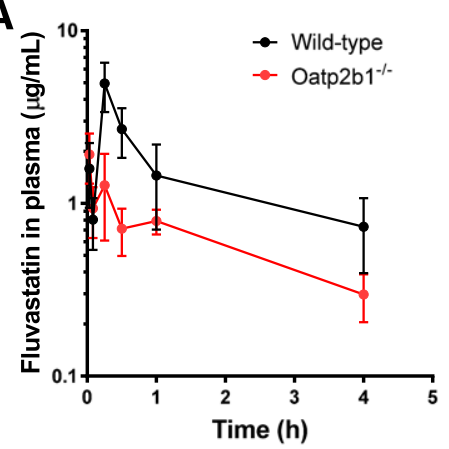

D

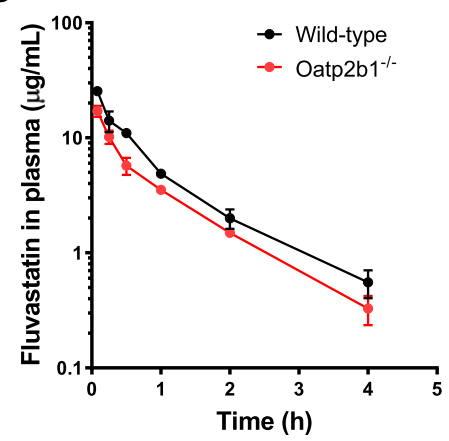

B

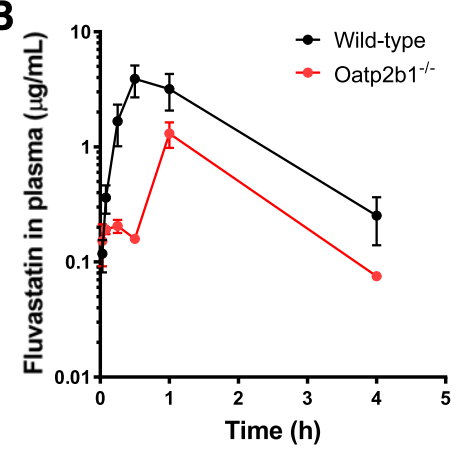

E

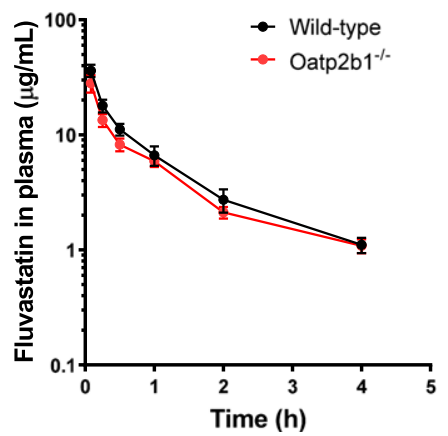

C

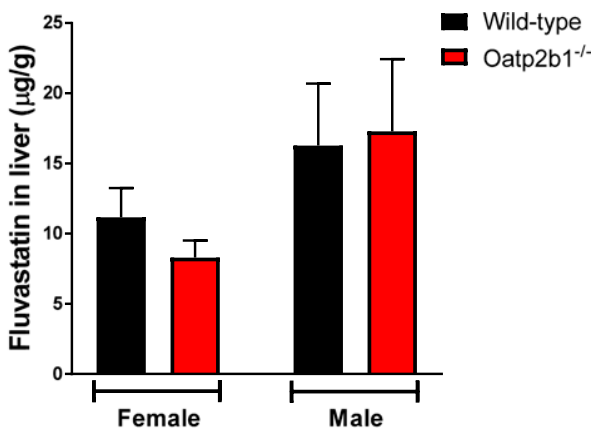

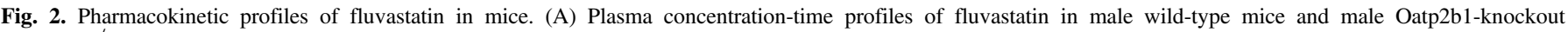

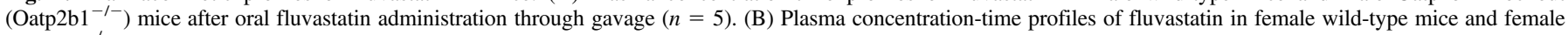

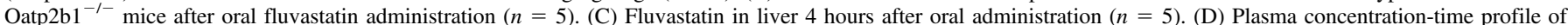

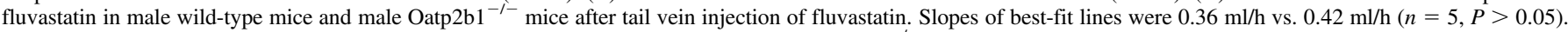

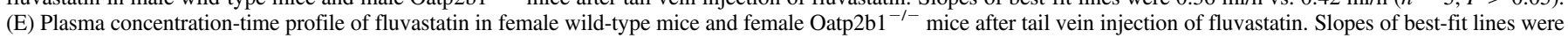
$0.36 \mathrm{ml} / \mathrm{h}$ vs. $0.32 \mathrm{ml} / \mathrm{h}(n=5, P>0.05)$.

expression levels of these genes were not significantly altered in male livers except for Oatp1b2 "transcripts" (Fig. 3A). No Oatp1b2 mRNA was detected in the intestines, as expected, and intestinal levels of Abcc2, Cyp2c65, and Cyp2c66 remained unchanged (Fig. 3B). Similar observations were made in female livers and intestines (Fig. 3C), although the expression of Cyp2c65 and Cyp2c66 in the female small intestine was slightly increased in female knockout mice (by 2.1-fold and 1.6-fold, respectively; $P<0.05$ ) (Fig. 3D).

Influence of OATP2B1 Inhibitor on Fluvastatin Absorption. Since several TKIs were previously determined to affect the function of OATPs, we next performed an in vitro inhibition screen involving 23 different TKIs and identified several novel inhibitors of OATP2B1 function using E3S as a probe substrate (Fig. 4A). The TKI erlotinib, previously reported to be both an inhibitor (Johnston et al., 2014) and a substrate of OATP2B1 (Bauer et al., 2018a), was also identified as a potent inhibitor in our screen. To ensure that the inhibitory properties of erlotinib are not substrate specific and/or species dependent, we confirmed that the uptake of fluvastatin was also diminished by erlotinib in cells overexpressing either OATP2B1 or Oatp2b1 (Fig. 4B). The pharmacokinetic profile of fluvastatin was then evaluated in wild-type and knockout mice in the presence or absence of pretreatment with oral erlotinib. The results indicated that erlotinib significantly decreased the AUC of fluvastatin in wild-type mice $(10.7 \pm 2.13 \mu \mathrm{g} \times \mathrm{h} / \mathrm{ml}$ vs. $5.80 \pm 0.47$ $\mu \mathrm{g} \times \mathrm{h} / \mathrm{ml} ; P<0.05$ ) (Fig. 4C) but not in knockout mice (Fig. 4D; Table 3). No statistically significant difference in fluvastatin liver exposure and liver to plasma ratio was detected between vehicle- or erlotinib-treated wild-type and knockout mice (Fig. 4E; Supplemental Fig. 4).

\section{Discussion}

The organic anion transporting polypeptide OATP2B1 was first cloned in 2000 (Tamai et al., 2000) and was reported to show pH-

TABLE 2

Influence of Oatp2b1 deficiency, sex, and route of administration on fluvastatin pharmacokinetics Data are presented as mean \pm S.E.M. ( $\mathrm{n}=4$ to 5 mice per group).

\begin{tabular}{|c|c|c|c|c|c|c|}
\hline \multirow[b]{2}{*}{ Genotype } & \multicolumn{2}{|c|}{ Oral } & \multicolumn{2}{|c|}{ Intravenous } & \multicolumn{2}{|c|}{ Bioavailability } \\
\hline & Wild-type & Oatp2b1 $1^{-1-}$ & Wild-type & Oatp2b1 $1^{-1-}$ & Wild-type & Oatp2b1 ${ }^{-/-}$ \\
\hline \multicolumn{7}{|l|}{ Females } \\
\hline $\mathrm{C}_{\max }(\mu \mathrm{g} / \mathrm{ml})$ & $3.90 \pm 1.20$ & $1.31 \pm 0.33^{*}$ & $36.2 \pm 4.42$ & $28.2 \pm 4.84$ & $31.5 \%$ & $12.8 \%$ \\
\hline $\begin{array}{l}\text { AUC }_{\text {last }}(\mu \mathrm{g} \times \mathrm{h} / \mathrm{ml}) \\
\text { Males }\end{array}$ & $7.80 \pm 2.15$ & $2.53 \pm 0.57^{*}$ & $24.8 \pm 3.44$ & $19.8 \pm 2.25$ & & \\
\hline $\mathrm{C}_{\max }(\mu \mathrm{g} / \mathrm{ml})$ & $4.96 \pm 1.58$ & $1.92 \pm 0.62 *$ & $25.5 \pm 1.53$ & $17.7 \pm 1.40 *$ & $29.6 \%$ & $20.5 \%$ \\
\hline $\mathrm{AUC}_{\text {last }}(\mu \mathrm{g} \times \mathrm{h} / \mathrm{ml})$ & $5.84 \pm 1.56$ & $2.59 \pm 0.45^{*}$ & $19.8 \pm 1.53$ & $12.6 \pm 0.58 *$ & & \\
\hline
\end{tabular}

${ }^{*} P<0.05$ vs. wild-type (two-sided student t-test). 

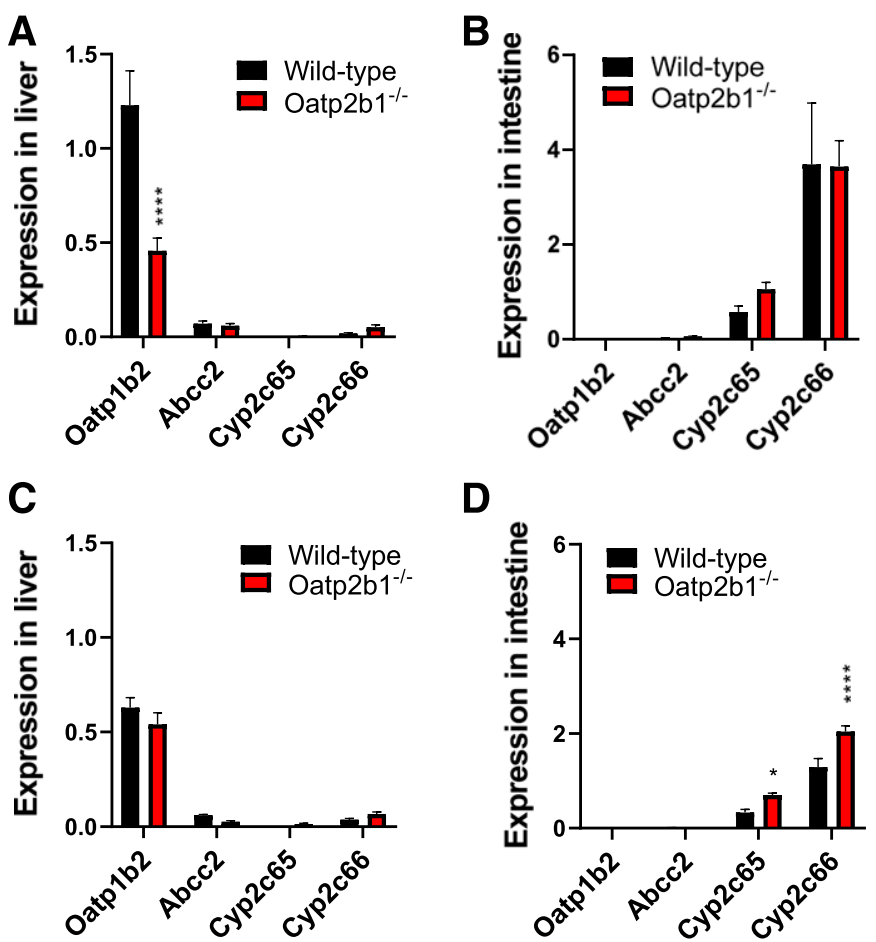

Fig. 3. Expression of transporters and enzymes of putative relevance to fluvastatin pharmacokinetics as determined by real-time qPCR. Relative mRNA expression of the Oatp1b2, Abcc2 (Mrp2), Cyp2c65, and Cyp2c66 genes was determined in livers (A and C) and small intestine (B and D) collected from male (A and B) and female (C and D) wild-type mice or male and female Oatp2b1-knockout (Oatp2b1 ${ }^{-1-}$ ) mice. Data are presented as means (bars) and S.E.M. (error bars) of four observations per genotype and sex. Expression values were normalized to the housekeeping gene, glyceraldehye-3-phosphate dehydrogenase. ${ }^{*} P<0.05$ vs. wildtype; $* * * * P<0.0001$ vs. wild-type.

sensitive activity with increased transport efficiency under acidic conditions (Kobayashi et al., 2003; Varma et al., 2011). Based on its relatively high expression levels in the small intestine (Badée et al., 2015) and the known clinically relevant drug interaction potential between OATP2B1 substrates and certain fruit juices (Tapaninen et al., 2011; Ieiri et al., 2012; Akamine et al., 2014), this transporter was long suspected to play a role in the intestinal absorption of drugs. However, the support for this supposition has mostly relied on drug-drug interaction data obtained after the consumption of fruit juices, and contradictory data on the exact localization of OATP2B1 in enterocytes have made it difficult to demonstrate causal relationships (Keiser et al., 2017). To address this question directly, we developed and characterized an Oatp2b1-deficient mouse model. While we were completing the current investigation, we became aware of a recent report describing a mouse model developed using the same targeting construct (Medwid et al., 2019). Similar to this earlier work, we found that Oatp2b1 was undetectable in major organs from the knockout mice and expressed highest in the liver of the wild-type mice. However, some minor discrepancies were observed with the previous report in that we found mRNA levels to be higher in the small intestine compared with kidney. This is in line with RNA expression data from The Human Protein Atlas (https://www.proteinatlas.org), which suggests that expression levels of OATP2B1 are highest in the liver, followed by small intestine and then kidney. Further investigation through mass spectrum-based proteomics could shed further light on possible strain- and species-dependent differences in the expression of this transporter in different organs.

Although OATP1B1 and OATP1B3 mediate the hepatic uptake of various known endogenous compounds, including conjugated and unconjugated bile acids and bilirubin-glucuronide, and have a confirmed physiologic role in bile acid homeostasis and bilirubin processing (Csanaky et al., 2011; van de Steeg et al., 2012; Slijepcevic et al., 2017; Suga et al., 2017), the endogenous function of OATP2B1 remains unclear. In agreement with the results reported by Medwid et al., 2019, blood serum chemistry analyses revealed only minor differences between wild-type mice and Oatp2b1-deficient littermates, possibly suggesting redundancy in the function of Oatps or other anion transporters. Interestingly, we found that Oatp2b1 deficiency was associated with a modest but statistically significant increase in blood urea nitrogen. Although this could be indicative of a mild renal impairment, serum creatinine levels were not different between mouse genotypes, suggesting that whole-body knockout of Oatp2b1 is unlikely to influence renal function to a clinically relevant extent. It is conceivable that the observed alteration of blood urea nitrogen could be linked to some other preexisting condition influencing the availability of peptides and amino acids to the liver, an altered processing of nutrients from the diet (Hosten, 1990), and/or differential expression of other transporters or enzymes of relevance to the amino acid metabolic pathway.

The pharmacological relevance of Oatp2b1 was evaluated in our mouse model with the known substrate drug, fluvastatin. Similar to previous reports on fexofenadine (Medwid et al., 2019), we found that the AUC of fluvastatin was decreased by about 2- to 3-fold in the knockout mice after a single oral dose, whereas the clearance of fluvastatin was independent of mouse genotypes. These studies suggest an important role for Oatp2b1 in the intestinal uptake of certain substrate drugs. Although the uptake of fluvastatin in the liver was not altered by Oatp2b1 deficiency, a contribution of this transporter to hepatocellular processing in wild-type mice cannot be excluded with certainty. Similar to most other statins, fluvastatin is a substrate of various other hepatic transporters, including Oatps (Higgins et al., 2014; Chang et al., 2019), and it is possible that the influence of Oatp2b1 deletion in the liver can be masked by compensatory upregulation of alternative, redundant uptake mechanisms. In this context, it is worth pointing out that deficiency of Oatp1a- and Oatp1b-type transporters in mice or pretreatment with the Oatp inhibitor rifampin (Bauer et al., 2018b) also did not alter the liver levels of fluvastatin (Chang et al., 2019).

Interestingly, unlike our current findings with fluvastatin, Medwid et al., 2019 found that measures of systemic exposure to oral rosuvastatin were not affected by Oatp2b1 deficiency, suggesting that the contribution of Oatp2b1 to the absorption and excretion of statins is drug specific. Although previous studies have demonstrated that the biliary excretion of statins in rodents is typically indirectly gated through Oatp1a/1b-type transporters in spite of their intrinsic differences in affinity (Iusuf et al., 2013; Higgins et al., 2014; Chang et al., 2019), this might not be the case for Oatp2b1. Since fluvastain has a higher affinity for OATP2B1 than rosuvastatin ( $\mathrm{Km}, 0.8$ vs. $6.42 \mu \mathrm{M}$, respectively), as determined in HEK293 cells (Noé et al., 2007; Kitamura et al., 2008) and given the significant sequence homology between the human and mouse transporter, Oatp2b1 could possibly be the predominant intestinal transporter for fluvastatin but not necessarily for rosuvastatin. In view of the notion that a considerable fraction of the oral fluvastatin dose was still absorbed in the knockout mice, it seems likely that there are other transporters expressed in the intestine that, together with Oatp2b1, differentially facilitate the absorption of statins.

When evaluating the possible compensatory effects of other fluvastatin transporters and metabolizing enzymes, we observed a significant reduction of Oatp $1 \mathrm{~b} 2 \mathrm{mRNA}$ in the livers collected from male but not female knockouts. However, this observation needs to be verified, as no such difference was reported by Medwid et al., 2019, and this change was not accompanied by any alteration in the liver uptake of fluvastatin (Fig. 2C). In humans, fluvastatin is predominantly metabolized by 

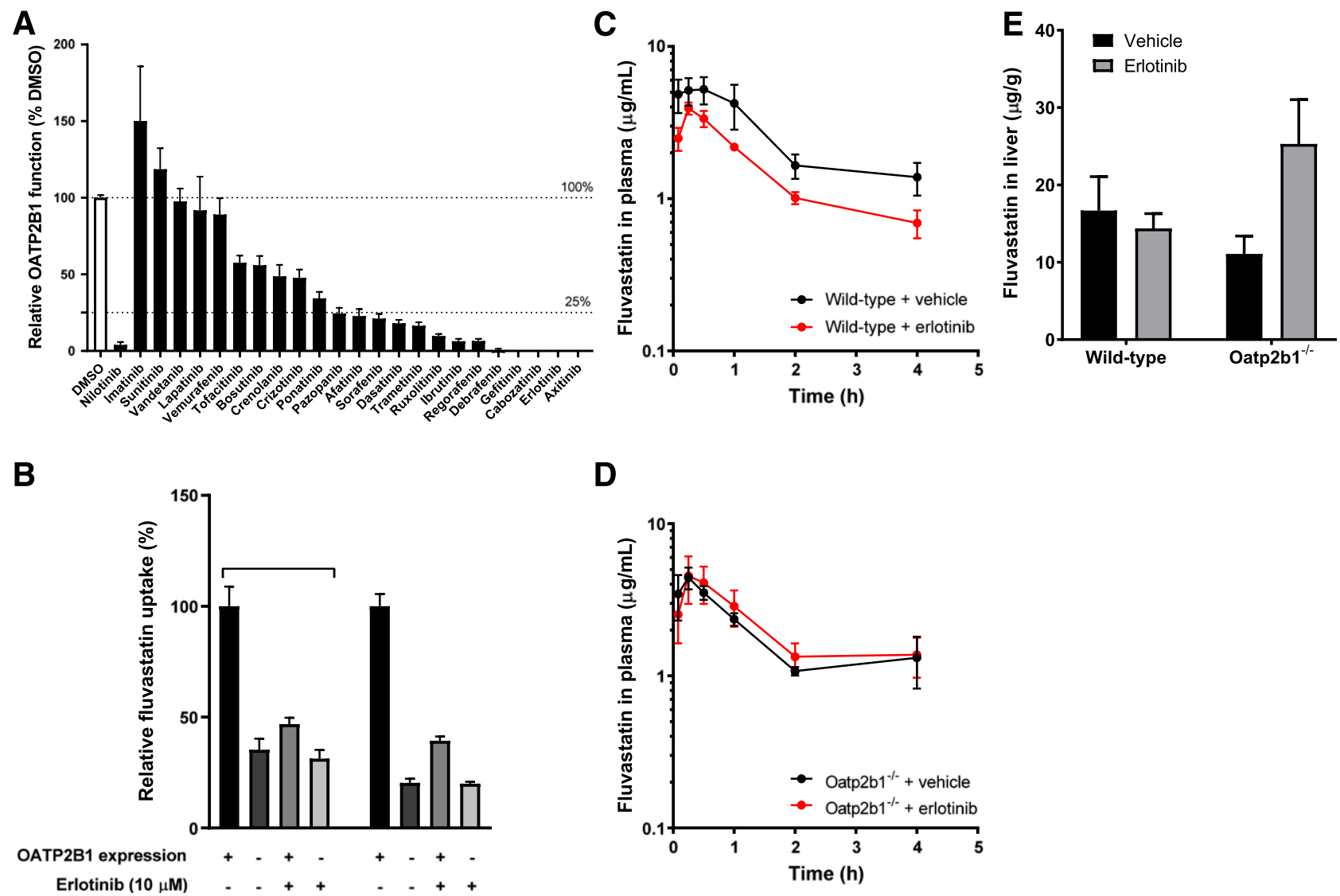

Fig. 4. Oatp2b1-mediated fluvastatin-erlotinib interaction. (A) Influence of TKIs on E3S uptake in HEK293 cells overexpressing human OATP2B1. Both HEK293OATP2B1 and HEK293-control vector cells were coincubated with designated amount of inhibitors and $\left[{ }^{3} \mathrm{H}\right]-\mathrm{E} 3 \mathrm{~S}(2.5 \mu \mathrm{M})$ for 5 minutes. Uptake values were normalized to that observed for the DMSO group. Data are presented as means (bars) and S.E.M. (error bars) of at least two experiments performed in triplicate $(n=6-12$ for TKIs; $n=69$ for DMSO). (B) Comparison between uptake of fluvastatin $(0.2 \mu \mathrm{M})$ in the presence or absence of erlotinib $(10 \mu \mathrm{M})$ in cells overexpressing OATP2B1 or Oatp2b1. (C and D) Plasma concentration-time profile of fluvastatin in mice pretreated with vehicle or erlotinib (100 mg/kg) in female wild-type mice (C) and female Oatp2b1-knockout $\left(\right.$ Oatp2b1 $\left.{ }^{-1-}\right)$ mice (D) $(n=4)$. (E) Fluvastatin concentration in liver 4 hours after oral administration $(n=4)$.

CYP2C9, but the specific mouse ortholog involved in this metabolic pathway remains unclear. There are four human CYP2C isoforms but 15 subfamily members in mice. We assessed expression levels of Cyp2c65 and Cyp2c66, the isoforms that are the closest homologs to human CYP2C9 in terms of protein sequence, and noticed a sexually dimorphic expression profile of Cyp2c66, which was expressed at significantly higher levels in the intestine of female but not male knockouts compared with wild-type littermates. Although this recorded difference did not influence the rate of elimination of fluvastatin after tail vein injection, caution is warranted when applying this mouse model to the study of other drugs for which clearance is more dependent on this elimination pathway.

To demonstrate translational relevance of the reported fluvastatinOatp2b1 interaction, several additional studies were performed involving OATP2B1 inhibitors. These studies revealed that pretreatment

TABLE 3

Influence of erlotinib on fluvastatin pharmacokinetics in female mice

Data are presented as means \pm S.E.M. ( $\mathrm{n}=4$ to 5 per group)

\begin{tabular}{lccc}
\hline Group & Parameter & + Vehicle & + Erlotinib \\
\hline Wild-type & $\mathrm{C}_{\max }(\mu \mathrm{g} / \mathrm{ml})$ & $6.89 \pm 0.72$ & $3.74 \pm 0.39$ \\
& $\mathrm{AUC}_{\text {last }}(\mu \mathrm{g} \times \mathrm{h} / \mathrm{ml})$ & $10.7 \pm 2.13$ & $5.80 \pm 0.47 *$ \\
Oatp2b1 $^{-1-}$ & $\mathrm{C}_{\max }(\mu \mathrm{g} / \mathrm{ml})$ & $4.93 \pm 1.04$ & $3.45 \pm 1.03$ \\
& $\mathrm{AUC}_{\text {last }}(\mu \mathrm{g} \times \mathrm{h} / \mathrm{ml})$ & $7.53 \pm 0.47$ & $6.89 \pm 1.70$ \\
\hline
\end{tabular}

$* P<0.05$ vs. vehicle (two-sided student t-test) with erlotinib reduced the exposure to fluvastain in wild-type mice but had no impact in knockout mice. This suggests that the influence of erlotinib on fluvastatin pharmacokinetics is exclusively due to an interaction through Oatp2b1 and suggests a vulnerability of this transporter-mediated process to potentially important drug-drug interactions. Erlotinib is a commonly used TKI that targets epidermal growth factor receptor and has been used in the treatment of non-small cell lung cancers, often as part of a multidrug regimen. An important area of research that has remained somewhat understudied is related to the notion that TKIs can interact widely with multiple, clinically relevant uptake transporters and can alter the pharmacokinetic profile of several other drugs given in combination (Hu et al., 2014; Johnston et al., 2014). Since Oatp2b1 has now been confirmed to influence the oral absorption of various prescription drugs, including fexofenadine (Medwid et al., 2019) and fluvastatin (this work), further studies aimed at identifying which TKIs interact with OATP2B1 and to what extent they can inhibit its function in vivo are indicated to avoid unintentional interactions that negatively affect the outcome of treatment. In the case of fluvastatin, the observed reduction in systemic exposure was not accompanied by altered levels in the liver and thus may not negatively influence its lipidlowering properties. Interestingly, as the major side effect of many statins, myotoxicity is well documented and known to be dosedependent (Neuvonen et al., 2006; Baigent et al., 2010), and the reduced systemic exposure to oral fluvastatin caused by Oatp2b1 deficiency may potentially act as a muscle-protective mechanism. Furthermore, OATP2B1 is itself expressed in skeletal muscles, unlike other statin 
uptake transporters, such as OATP1B1, OATP1B3, OAT1 and OAT3 (Knauer et al., 2010), suggesting this transporter may be involved in regulating local exposure to statins. This possibility and the potential utility of OATP2B1 inhibitors such as erlotinib (given intravenously) to offer protection against statin-induced myopathy by influencing tissue distribution profiles are currently under further investigation.

Overall, our study suggests that Oatp2b1-deficient mice provide a valuable tool to study the in vivo importance of this transporter and suggests that it may play a role in the absorption of certain substrate drugs such as fluvastatin. In addition, we have identified novel potent inhibitors of OATP2B1 among the class of TKIs, a rapidly expanding class of drugs used in various therapeutic areas that may cause drug-drug interactions with OATP2B1 substrates. Future study of the association between statin levels and statin-induced myopathy and efficacy, and the connection with OATP2B1-mediated transport, is warranted.

\section{Acknowledgments}

We would like to thank Dr. Vincenzo Coppola (The Ohio State University, Columbus, $\mathrm{OH}$ ) for assistance with the generation of Oatp2b1-deficient mice.

\section{Authorship Contributions}

Participated in research design: $\mathrm{Hu}$, Baker, Sparreboom.

Conducted experiments: Chen, Li.

Contributed new reagents or analytic tools: Gibson, Fu.

Performed data analysis: Chen, Gibson.

Wrote or contributed to the writing of the manuscript: Chen, Sparreboom.

\section{References}

Akamine Y, Miura M, Komori H, Saito S, Kusuhara H, Tamai I, Ieiri I, Uno T, and Yasui-Furukori N (2014) Effects of one-time apple juice ingestion on the pharmacokinetics of fexofenadine enantiomers. Eur J Clin Pharmacol 70:1087-1095.

Badée J, Achour B, Rostami-Hodjegan A, and Galetin A (2015) Meta-analysis of expression of hepatic organic anion-transporting polypeptide (OATP) transporters in cellular systems relative to human liver tissue. Drug Metab Dispos 43:424-432.

Baigent C, Blackwell L, Emberson J, Holland LE, Reith C, Bhala N, Peto R, Barnes EH, Keech A, Simes J, et al.; Cholesterol Treatment Trialists' (CTT) Collaboration (2010) Efficacy and safety of more intensive lowering of LDL cholesterol: a meta-analysis of data from 170,000 participants in 26 randomised trials. Lancet 376:1670-1681.

Bauer M, Matsuda A, Wulkersdorfer B, Philippe C, Traxl A, Özvegy-Laczka C, Stanek J, Nics L, Klebermass EM, Poschner S, et al. (2018a) Influence of OATPs on hepatic disposition of erlotinib measured with positron emission tomography. Clin Pharmacol Ther 104:139-147.

Bauer M, Traxl A, Matsuda A, Karch R, Philippe C, Nics L, Klebermass EM, Wulkersdorfer B Weber M, Poschner S, et al. (2018b) Effect of rifampicin on the distribution of [ ${ }^{11}$ C]erlotinib to the liver, a translational PET study in humans and in mice. Mol Pharm 15:4589-4598.

Chang JH, Zhang X, Messick K, Chen YC, Chen E, Cheong J, and Ly J (2019) Unremarkable impact of Oatp inhibition on the liver concentration of fluvastatin, lovastatin and pitavastatin in wild-type and Oatp1a/1b knockout mouse. Xenobiotica 49:602-610.

Chen M, Neul C, Schaeffeler E, Frisch F, Winter S, Schwab M, Koepsell H, Hu S, Laufer S, Baker SD, et al. (2020) Sorafenib activity and disposition in liver cancer does not depend on organic cation transporter 1. Clin Pharmacol Ther 107:227-237.

Chu X, Bleasby K, and Evers R (2013) Species differences in drug transporters and implications for translating preclinical findings to humans. Expert Opin Drug Metab Toxicol 9:237-252.

Csanaky IL, Lu H, Zhang Y, Ogura K, Choudhuri S, and Klaassen CD (2011) Organic aniontransporting polypeptide $1 \mathrm{~b} 2$ (Oatp1b2) is important for the hepatic uptake of unconjugated bile acids: studies in Oatp1b2-null mice. Hepatology 53:272-281.

Drozdzik M, Gröer C, Penski J, Lapczuk J, Ostrowski M, Lai Y, Prasad B, Unadkat JD, Siegmund W, and Oswald S (2014) Protein abundance of clinically relevant multidrug transporters along the entire length of the human intestine. Mol Pharm 11:3547-3555.

Fujita D, Saito Y, Nakanishi T, and Tamai I (2016) Organic anion transporting polypeptide (OATP) 2B1 contributes to gastrointestinal toxicity of anticancer drug SN-38, active metabolite of irinotecan hydrochloride. Drug Metab Dispos 44:1-7.

Higgins JW, Bao JQ, Ke AB, Manro JR, Fallon JK, Smith PC, and Zamek-Gliszczynski MJ (2014) Utility of Oatpla/1b-knockout and OATP1B1/3-humanized mice in the study of OATPmediated pharmacokinetics and tissue distribution: case studies with pravastatin, atorvastatin, simvastatin, and carboxydichlorofluorescein. Drug Metab Dispos 42:182-192.

Hosten AO (1990) BUN and creatinine, in Clinical Methods: The History, Physical, and Laboratory Examinations (Walker HK, Hall WD, and Hurst JW eds), Butterworth Publishers, a division of Reed Publishing, Boston:chapter 193.
Hu S, Mathijssen RH, de Bruijn P, Baker SD, and Sparreboom A (2014) Inhibition of OATP1B1 by tyrosine kinase inhibitors: in vitro-in vivo correlations. Br J Cancer 110:894-898.

Ieiri I, Doi Y, Maeda K, Sasaki T, Kimura M, Hirota T, Chiyoda T, Miyagawa M, Irie S, Iwasaki K, et al. (2012) Microdosing clinical study: pharmacokinetic, pharmacogenomic (SLCO2B1), and interaction (grapefruit juice) profiles of celiprolol following the oral microdose and therapeutic dose. J Clin Pharmacol 52:1078-1089.

Iusuf D, van Esch A, Hobbs M, Taylor M, Kenworthy KE, van de Steeg E, Wagenaar E, and Schinkel AH (2013) Murine Oatpla/lb uptake transporters control rosuvastatin systemic exposure without affecting its apparent liver exposure. Mol Pharmacol 83:919-929.

Johnson M, Patel D, Matheny C, Ho M, Chen L, and Ellens H (2017) Inhibition of intestinal OATP2B1 by the calcium receptor antagonist ronacaleret results in a significant drug-drug interaction by causing a 2-fold decrease in exposure of rosuvastatin. Drug Metab Dispos $\mathbf{4 5}$ : $27-34$.

Johnston RA, Rawling T, Chan T, Zhou F, and Murray M (2014) Selective inhibition of human solute carrier transporters by multikinase inhibitors. Drug Metab Dispos 42:1851-1857.

Kaliss N and Pressman D (1950) Plasma and blood volumes of mouse organs, as determined with radioactive iodoproteins. Proc Soc Exp Biol Med 75:16-20.

Kashihara Y, Ieiri I, Yoshikado T, Maeda K, Fukae M, Kimura M, Hirota T, Matsuki S, Irie S, Izumi N, et al. (2017) Small-dosing clinical study: pharmacokinetic, pharmacogenomic (SLCO2B1 and ABCG2), and interaction (atorvastatin and grapefruit juice) profiles of 5 probes for OATP2B1 and BCRP. J Pharm Sci 106:2688-2694.

Keiser M, Kaltheuner L, Wildberg C, Müller J, Grube M, Partecke LI, Heidecke CD, and Oswald S (2017) The organic anion-transporting peptide $2 \mathrm{~B} 1$ is localized in the basolateral membrane of the human jejunum and Caco-2 monolayers. J Pharm Sci 106:2657-2663.

Kitamura S, Maeda K, Wang Y, and Sugiyama Y (2008) Involvement of multiple transporters in the hepatobiliary transport of rosuvastatin. Drug Metab Dispos 36:2014-2023.

Knauer MJ, Urquhart BL, Meyer zu Schwabedissen HE, Schwarz UI, Lemke CJ, Leake BF, Kim RB, and Tirona RG (2010) Human skeletal muscle drug transporters determine local exposure and toxicity of statins. Circ Res 106:297-306.

Kobayashi D, Nozawa T, Imai K, Nezu J, Tsuji A, and Tamai I (2003) Involvement of human organic anion transporting polypeptide OATP-B (SLC21A9) in pH-dependent transport across intestinal apical membrane. J Pharmacol Exp Ther 306:703-708.

Leblanc AF, Huang KM, Uddin ME, Anderson JT, Chen M, and Hu S (2018) Murine pharmacokinetic studies. Bio Protoc 8:e3056.

Medwid S, Li MMJ, Knauer MJ, Lin K, Mansell SE, Schmerk CL, Zhu C, Griffin KE, Yousif MD, Dresser GK, et al. (2019) Fexofenadine and rosuvastatin pharmacokinetics in mice with targeted disruption of organic anion transporting polypeptide 2B1. Drug Metab Dispos 47:832-842.

Meier Y, Eloranta JJ, Darimont J, Ismair MG, Hiller C, Fried M, Kullak-Ublick GA, and Vavricka SR (2007) Regional distribution of solute carrier mRNA expression along the human intestinal tract. Drug Metab Dispos 35:590-594.

Neuvonen PJ, Niemi M, and Backman JT (2006) Drug interactions with lipid-lowering drugs: mechanisms and clinical relevance. Clin Pharmacol Ther 80:565-581.

Noé J, Portmann R, Brun ME, and Funk C (2007) Substrate-dependent drug-drug interactions between gemfibrozil, fluvastatin and other organic anion-transporting peptide (OATP) substrates on OATP1B1, OATP2B1, and OATP1B3. Drug Metab Dispos 35:1308-1314.

Nozawa T, Imai K, Nezu J, Tsuji A, and Tamai I (2004) Functional characterization of pH-sensitive organic anion transporting polypeptide OATP-B in human. J Pharmacol Exp Ther 308:438-445.

Prasad B, Gaedigk A, Vrana M, Gaedigk R, Leeder JS, Salphati L, Chu X, Xiao G, Hop C, Evers R, et al. (2016) Ontogeny of hepatic drug transporters as quantified by LC-MS/MS proteomics. Clin Pharmacol Ther 100:362-370.

Slijepcevic D, Roscam Abbing RLP, Katafuchi T, Blank A, Donkers JM, van Hoppe S, de Waart DR, Tolenaars D, van der Meer JHM, Wildenberg M, et al. (2017) Hepatic uptake of conjugated bile acids is mediated by both sodium taurocholate cotransporting polypeptide and organic anion transporting polypeptides and modulated by intestinal sensing of plasma bile acid levels in mice. Hepatology 66:1631-1643

Suga T, Yamaguchi H, Sato T, Maekawa M, Goto J, and Mano N (2017) Preference of conjugated bile acids over unconjugated bile acids as substrates for OATP1B1 and OATP1B3. PLoS One 12:e0169719.

Tamai I, Nezu J, Uchino H, Sai Y, Oku A, Shimane M, and Tsuji A (2000) Molecular identification and characterization of novel members of the human organic anion transporter (OATP) family. Biochem Biophys Res Commun 273:251-260.

Tapaninen T, Neuvonen PJ, and Niemi M (2011) Orange and apple juice greatly reduce the plasma concentrations of the OATP2B1 substrate aliskiren. Br J Clin Pharmacol 71:718-726.

van de Steeg E, Stránecký V, Hartmannová H, Nosková L, Hřebíćek M, Wagenaar E, van Esch A, de Waart DR, Oude Elferink RP, Kenworthy KE, et al. (2012) Complete OATP1B1 and OATP1B3 deficiency causes human Rotor syndrome by interrupting conjugated bilirubin reuptake into the liver. J Clin Invest 122:519-528.

Varma MV, Rotter CJ, Chupka J, Whalen KM, Duignan DB, Feng B, Litchfield J, Goosen TC, and El-Kattan AF (2011) pH-sensitive interaction of HMG-CoA reductase inhibitors (statins) with organic anion transporting polypeptide 2B1. Mol Pharm 8:1303-1313.

Zamek-Gliszczynski MJ, Taub ME, Chothe PP, Chu X, Giacomini KM, Kim RB, Ray AS, Stocker SL, Unadkat JD, Wittwer MB, et al.; International Transporter Consortium (2018) Transporters in drug development: 2018 ITC recommendations for transporters of emerging clinical importance. Clin Pharmacol Ther 104:890-899.

Address correspondence to: Alex Sparreboom, Division of Pharmaceutics and Pharmacology, College of Pharmacy, The Ohio State University, BRT, Room 0408, 460 West 12th Avenue, Columbus, OH 43210. E-mail: sparreboom.1@osu.edu 